This document is confidential and is proprietary to the American Chemical Society and its authors. Do not copy or disclose without written permission. If you have received this item in error, notify the sender and delete all copies.

\title{
The Two Faces of Ciprofloxacin: Investigation of Proton Transfer in Solid State Transformations
}

\begin{tabular}{|r|l|}
\hline Journal: & Crystal Growth \& Design \\
\hline Manuscript ID & cg-2016-01283h.R1 \\
\hline Manuscript Type: & Article \\
\hline Date Submitted by the Author: & n/a \\
\hline Complete List of Authors: & $\begin{array}{l}\text { Mesallati, Hanah; University of Dublin Trinity College, School of Pharmacy } \\
\text { and Pharmaceutical Sciences } \\
\text { Mugheirbi, Naila; Trinity College Dublin, School of pharmacy and } \\
\text { Pharmaceutical Sciences } \\
\text { Tajber, Lidia; Trinity College Dublin, School of Pharmacy and } \\
\text { Pharmaceutical Sciences }\end{array}$ \\
\hline
\end{tabular}

SCHOLARONE ${ }^{m}$

Manuscripts 
Cover Page

\title{
The Two Faces of Ciprofloxacin: Investigation of Proton Transfer in Solid State Transformations
}

\author{
Mesallati H, Mugheirbi NA, and Tajber $L^{*}$ \\ School of Pharmacy and Pharmaceutical Sciences, Trinity College Dublin, College Green, \\ Dublin 2, Ireland \\ *Corresponding author: \\ Tel.: +353 18962787 ; fax: +353 18962810 . \\ http://pharmacy.tcd.ie/staff/tajber-cv.php?uname=ltajber \\ E-mail address: 1tajber@tcd.ie (Lidia Tajber)
}

\begin{abstract}
Ciprofloxacin (CIP) can exist in two different forms: the zwitterion and the unionized form. While the crystal structure of each has been described independently, the ability of CIP to transform from one to the other in the solid state has not been described. The crystal structures of unionized and zwitterionic CIP were therefore compared using computational methods, including their packing arrangement, hydrogen bonding, packing energy, intermolecular potentials and HOMO/LUMO energy gap. The pure amorphous form of CIP has also never been prepared or studied. Ball milling, cryomilling and spray drying were used in this study to prepare partially and fully amorphous CIP for the first time. The physical characteristics were examined by PXRD, FTIR and DSC. CIP proved to be very difficult to amorphize, and only spray drying in pure water resulted in a fully amorphous product. It was discovered that while most processing methods resulted in the more stable zwitterionic form of the drug, spray drying in an ethanol/water mixture produced the unionized form. The zwitterion was found to convert to the unionized form upon heating to its melting point, whereas the reverse transformation occurred when unionized CIP was exposed to high humidity. This study thus provides insight into the proton transfer which can occur in a zwitterionic drug in the solid state, and the resultant changes to its crystal structure.
\end{abstract}

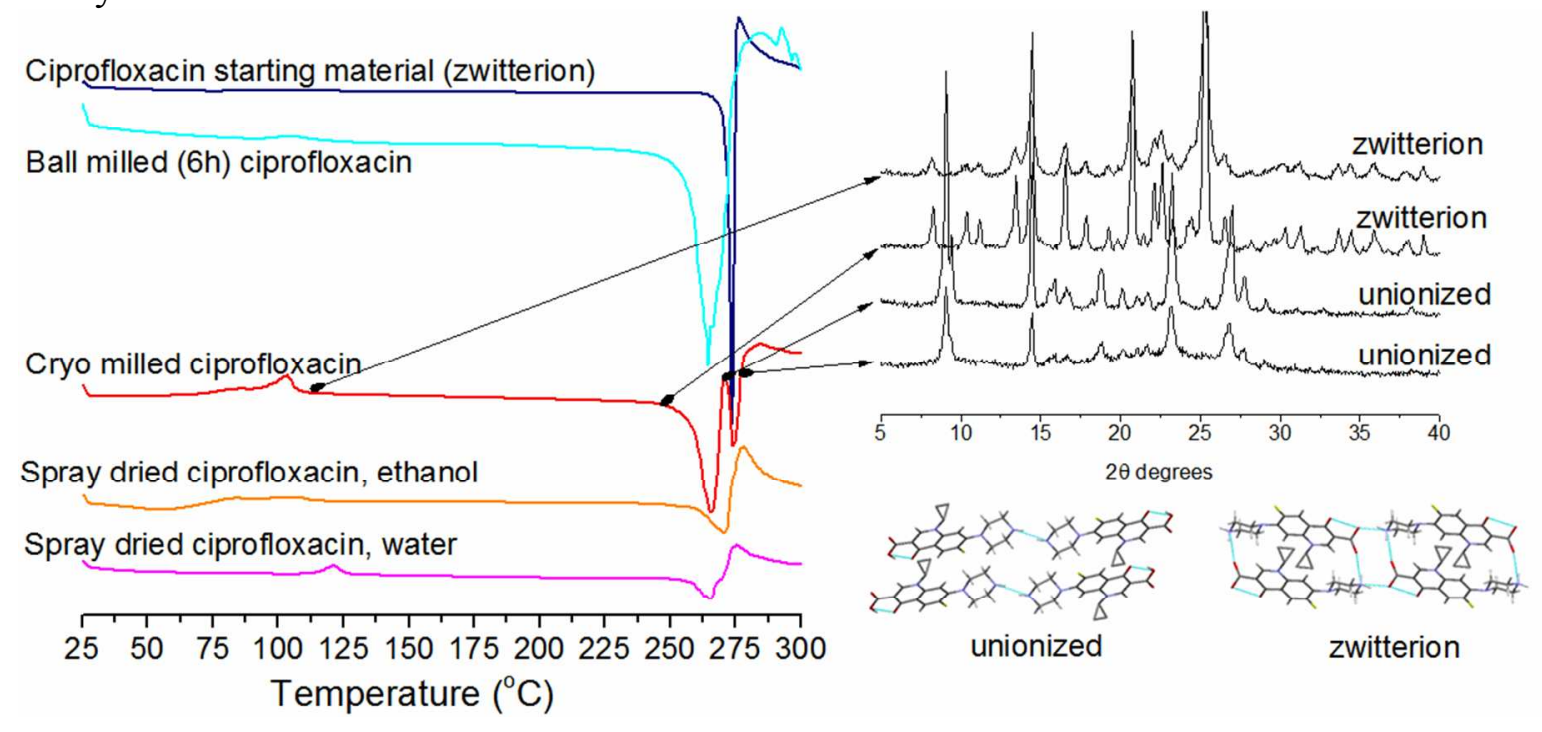




\title{
Title Page \\ The Two Faces of Ciprofloxacin: Investigation of Proton Transfer in Solid State Transformations
}

\author{
Hanah Mesallati, Naila A. Mugheirbi, and Lidia Tajber* \\ School of Pharmacy and Pharmaceutical Sciences, Trinity College Dublin, College Green, \\ Dublin 2, Ireland
}

\footnotetext{
*School of Pharmacy and Pharmaceutical Sciences, Trinity College Dublin, College Green, Dublin 2, Ireland. Tel: +35318962787. Email: 1tajber@tcd.ie.
} 


\section{Abstract}

Ciprofloxacin (CIP) can exist in two different forms: the zwitterion and the unionized form. While the crystal structure of each has been described independently, the ability of CIP to transform from one to the other in the solid state has not been described. The crystal structures of unionized and zwitterionic CIP were therefore compared using computational methods, including their packing arrangement, hydrogen bonding, packing energy, intermolecular potentials and HOMO/LUMO energy gap. The pure amorphous form of this drug has also never been prepared or studied. Ball milling, cryomilling and spray drying were used in this study to prepare partially and fully amorphous CIP for the first time. The physical characteristics, and in particular ionization state, of these samples were examined by PXRD, FTIR and DSC. Analysis of the crystal packing of unionized and zwitterionic CIP revealed that the presence of ionic interactions between the charged groups of the latter results in a denser and more stable crystal lattice. A greater HOMO/LUMO energy gap was also calculated for this sample, confirming its lower reactivity. CIP proved to be very difficult to amorphize, and only spray drying in pure water resulted in a fully amorphous product. It was discovered that while most processing methods resulted in the more stable zwitterionic form of the drug, spray drying in an ethanol/water mixture produced the unionized form. The zwitterion was found to convert to the unionized form upon heating to its melting point, whereas the reverse transformation occurred when unionized CIP was exposed to high humidity. This study thus provides insight into the proton transfer which can occur in a zwitterionic drug in the solid state, and the resultant changes to its crystal structure.

Keywords: Ciprofloxacin, amorphous, zwitterion, ball milling, spray drying, proton transfer. 


\section{Introduction}

Ciprofloxacin (CIP), or 1-cyclopropyl-6-fluoro-4-oxo-7-(piperazin-1-yl)-1,4-dihydroquinoline-3carboxylic acid, is a second generation fluoroquinolone which was first marketed in 1986. It is a wide spectrum antibiotic, with high activity against Gram-negative species of bacteria and goodto-moderate activity against Gram-positive species. ${ }^{1,2}$ It is also effective against atypical organisms such as Legionella pneumophila, Chlamydia trachomatis, Mycobacterium tuberculosis and Mycoplasma hominis. ${ }^{3,4}$ Anhydrous CIP is an interesting molecule, as it can exist in two different forms: the unionized form (Figure 1a) and the zwitterion (Figure 1b). However it is the zwitterion that is usually present in the solid state, and that is available commercially. The crystal structures of the unionized form of CIP (CIP_UI) and the zwitterion (CIP_ZW) have been described by Mahapatra et al and Fabbiani et al, respectively ${ }^{5,6}$ (ORTEP representations of both structures are presented in Figure SI.1).

(a)

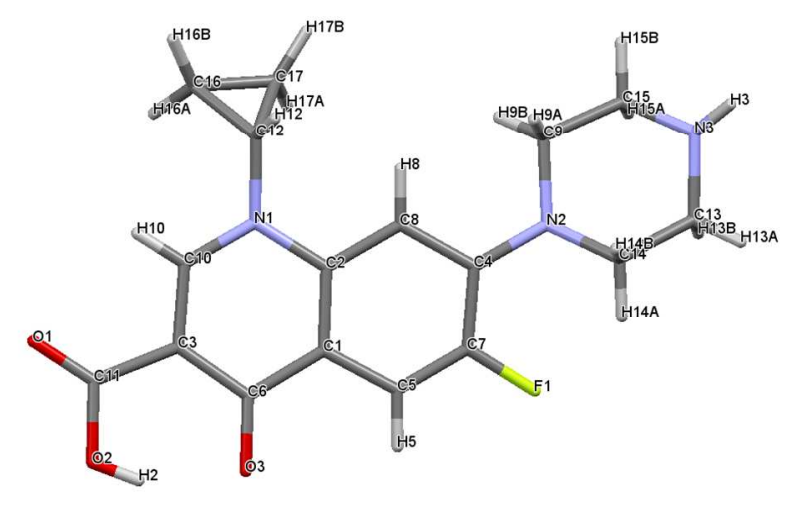


(b)

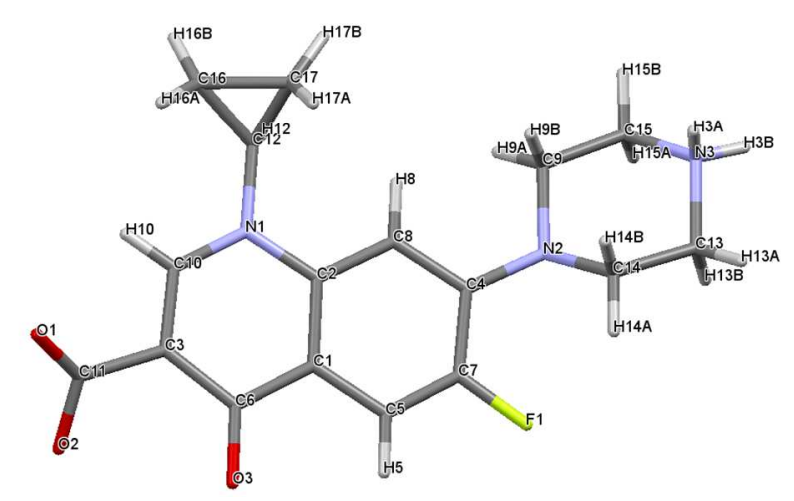

Figure 1. Chemical structures with atom labels of (a) unionized CIP and (b) CIP zwitterion.

In solution, the carboxylic acid and piperazine group of CIP can ionize, depending on the $\mathrm{pH}$ of the surrounding media. In the neutral $\mathrm{pH}$ range CIP is zwitterionic and has an overall neutral charge, making it practically insoluble in aqueous media. ${ }^{7}$ The zwitterion may also form several resonance structures. ${ }^{8}$ The solubility of CIP in water has been reported as 0.06 and $0.08 \mathrm{mg} / \mathrm{mL}$ at $25{ }^{\circ} \mathrm{C}$ and $37{ }^{\circ} \mathrm{C}$ respectively. ${ }^{9} \mathrm{CIP}$ is also poorly soluble in other common solvents such as ethanol, methanol, propanol, dichloromethane, acetone and chloroform..$^{10,11,12}$

The poor solubility of CIP may also be attributed to the strength of its crystal lattice, resulting in solid state-limited solubility. Intermolecular interactions, such as hydrogen bonding, Van der Waals and $\pi-\pi$ interactions, inhibit the dissociation of drug molecules from the crystal lattice upon addition to water. ${ }^{13}$ One method of improving the solubility of such drugs is amorphization. The amorphous form does not possess long range order, and is the most energetic solid state. ${ }^{14,15}$ Amorphous drugs are therefore more soluble than their crystalline counterparts, as less energy is required for the molecules to enter solution. ${ }^{16}$ However, due to their excess free energy, amorphous solids are intrinsically unstable and prone to crystallization. ${ }^{14}$ This is more likely to occur at temperatures above their glass transition temperature $\left(\mathrm{T}_{\mathrm{g}}\right)$, as the increased molecular 
mobility enables nucleation and crystallization. ${ }^{17}$ Amorphous drugs are also more hygroscopic than their crystalline forms, due to their irregular molecular arrangement and larger free volume. Water can therefore absorb into the internal structure of the material rather than just adsorb to the surface. ${ }^{17,18}$ Water absorption can negatively affect drug stability by increasing the rate of crystallization. ${ }^{19}$ This is due to a lowering of the $\mathrm{T}_{\mathrm{g}}$, increase in molecular mobility and plasticization. $^{17,20}$

Unlike many other poorly soluble drugs, there is very little information in the literature regarding the formation of amorphous CIP in any form. As far as the authors are aware, the preparation of pure amorphous CIP has never been described. A few formulations containing amorphous CIP have been prepared, however, including amorphous salts of CIP and succinic acid, ${ }^{9}$ dextran sulfate nanoplexes, ${ }^{21,22}$ and microparticles containing chitosan and dextran. ${ }^{23}$ In contrast, the production of other fluoroquinolones in the amorphous state has been more extensively reported. Norfloxacin, which possesses an ethyl group in the place of CIP's cyclopropyl group, has been produced in the pure amorphous form via spray drying and quench cooling. This form of the drug was found to be in the unionized state, whereas anhydrous crystalline norfloxacin is zwitterionic. $^{24,25}$ Amorphous moxifloxacin $\mathrm{HCl}$ and levofloxacin $\mathrm{HCl}$ have also been prepared by spray drying and solvent evaporation, respectively, ${ }^{26,27}$ whereas gemifloxacin has been synthesized in the amorphous form. ${ }^{28}$

Due to the absence of research in this area, the primary aim of this study was to prepare the pure amorphous form of CIP. Ball milling, cryomilling and spray drying were attempted for this purpose. Powder X-ray Diffraction (PXRD), Differential Scanning Calorimetry (DSC) and Fourier Transform Infrared Spectrometry (FTIR) were used to confirm the amorphous nature or otherwise of the resultant samples and their ionization state, and to find the $\mathrm{T}_{\mathrm{g}}$ of CIP. CIP has 
been reported to undergo thermal decomposition following melting, ${ }^{9}$ however this has never been fully investigated. In order to rule out the use of melting techniques, such as quench cooling, for the amorphization of CIP, its degradation upon heating to the onset and endset of melting was investigated. The effect of such heating on its ionization state was also examined. Experimental data was supported by quantum mechanics calculations. Finally, the effect of water uptake on the unionized form of CIP was examined by Dynamic Vapor Sorption (DVS).

\section{Materials}

Anhydrous ciprofloxacin was obtained from Carbosynth Limited, Berkshire, UK. Acetonitrile was obtained from Sigma-Aldrich Ireland Ltd., Arklow, Ireland. All other chemicals and solvents were of analytical grade.

\section{Methods}

\section{Ball Milling}

Raw CIP was ball milled at room temperature using a Retsch ${ }^{\circledR}$ planetary ball mill PM 100 (Haan, Germany). $2 \mathrm{~g}$ of powder was added to $50 \mathrm{~mL}$ stainless steel grinding bowls. Three stainless steel milling balls $20 \mathrm{~mm}$ in diameter and weighing $32 \mathrm{~g}$ each were used. The drug was milled for 6 hours in total, in intervals of 15 min with 10 min breaks in between. After 1, 2, 4 and 6 hours, small samples of powder were taken for analysis by PXRD.

\section{Cryomilling}


A Retsch ${ }^{\circledR}$ CryoMill (Haan, Germany) was used to cryomill $0.5 \mathrm{~g}$ of pure CIP raw material. The drug was sealed in a grinding jar and immersed in liquid nitrogen for a few minutes. CIP was then milled for 6 cycles, consisting of 3 min of grinding followed by a 2 min break.

\section{Spray Drying}

A Büchi B-290 mini spray dryer (Flawil, Switzerland) with a $1.5 \mathrm{~mm}$ cap and $0.7 \mathrm{~mm}$ tip was used to spray dry pure CIP. The pump speed was set to $30 \%(9-10 \mathrm{~mL} / \mathrm{min})$, and the aspirator to $100 \%$. A mixture of nitrogen (with a pressure of 6 bar) and air was used as the drying gas. Two different solvents were used to produce pure spray dried CIP. In the first case, an excess of the drug was added to $1 \mathrm{~L}$ of a 9:1 mixture of ethanol and water, which was stirred overnight. The next day the solution was filtered to remove any undissolved drug, and then spray dried using an inlet temperature of $78^{\circ} \mathrm{C}$. This procedure was then repeated using pure water and an inlet temperature of $100{ }^{\circ} \mathrm{C}$.

\section{Powder X-ray Diffraction (PXRD)}

PXRD was carried out to determine whether samples were amorphous or partially/fully crystalline. This was performed at room temperature using a benchtop Rigaku MiniflexII X-ray diffractometer (Tokyo, Japan) and a Haskris cooler (Illinois, USA). The samples were scanned from 5 to $402 \theta$ degrees with a step width of 0.05 , scan rate of $0.05^{\circ}$ per second and signal collection time per step of 1 second. The tube $(\mathrm{Cu}, 1 \mathrm{~kW}$ normal focus $)$ output voltage and current were $30 \mathrm{kV}$ and $15 \mathrm{~mA}$, respectively.

\section{Differential Scanning Calorimetry (DSC)}


DSC was carried out using a Mettler Toledo DSC (Schwerzenbach, Switzerland) with a RP-100 LabPlant refrigerated cooling system (Filey, UK), which was calibrated using an indium standard. The purge gas used was nitrogen. Approximately 5-10 mg samples were analyzed in sealed $40 \mu \mathrm{L}$ aluminum pans with pierced lids. All samples were heated from 25 to $300{ }^{\circ} \mathrm{C}$ at 10 ${ }^{\mathrm{o}} \mathrm{C} / \mathrm{min}$.

\section{High-Speed DSC (HSDSC)}

HSDSC was performed using a PerkinElmer Diamond DSC (Waltham, MA, USA) and ULSP B.V. 130 cooling system (Ede, Netherlands). The instrument was calibrated using an indium standard. Approximately 3-5 mg samples were analyzed in $40 \mu \mathrm{L}$ aluminum pans with sealed aluminum lids. A helium gas flow of $60 \mathrm{~mL} / \mathrm{min}$ was controlled with a PerkinElmer Thermal Analysis Gas Station. Crystalline and cryomilled CIP were heated from 25 to $300{ }^{\circ} \mathrm{C}$ at $50-500$ ${ }^{\circ} \mathrm{C} / \mathrm{min}$. To allow for water evaporation, cryomilled CIP was first heated from 25 to $70{ }^{\circ} \mathrm{C}$, allowed to cool to $25{ }^{\circ} \mathrm{C}$, and then reheated to $300{ }^{\circ} \mathrm{C}$.

\section{Temperature-Modulated Differential Scanning Calorimetry (MTDSC) - StepScanTM}

A PerkinElmer Diamond DSC, as described above, was used to detect the $\mathrm{T}_{\mathrm{g}}$ of amorphous CIP. Nitrogen was used as the purge gas at a flow rate of $40 \mathrm{~mL} / \mathrm{min}$. Samples were prepared as described for HSDSC, and were heated at $5{ }^{\circ} \mathrm{C} / \mathrm{min}$ in steps of $2{ }^{\circ} \mathrm{C}$. Between each step the temperature was held constant for $1 \mathrm{~min}$. The specific heat of the glass transition was calculated from the enthalpy flow using the area algorithm.

\section{Thermogravimetric Analysis (TGA)}


TGA was carried out on CIP raw material and cryomilled CIP using a Mettler TG50 measuring module coupled to a Mettler Toledo MT5 balance (Schwerzenbach, Switzerland). Approximately 8-10 mg samples were analyzed in open aluminum pans, using nitrogen as the purge gas. Samples were heated from 25 to $300{ }^{\circ} \mathrm{C}$ at a rate of $10{ }^{\circ} \mathrm{C} / \mathrm{min}$. Mettler Toledo STARe software (version 6.10) was used to analyze the thermograms.

\section{Solid State Fourier Transform Infrared Spectroscopy (FTIR)}

FTIR was performed using a Spectrum One FT-IR Spectrometer (Perkin Elmer, Connecticut, USA) equipped with Spectrum Software version 6.1. A spectral range of $450-4000 \mathrm{~cm}^{-1}$, resolution of $4 \mathrm{~cm}^{-1}$, scan number of 10 and scan speed of $0.2 \mathrm{~cm} / \mathrm{s}$ were used. $\mathrm{KBr}$ disks were produced by direct compression, using a pressure of approximately 10 bar for $1 \mathrm{~min}$. A sample loading of $1 \%$ was used. Deconvolution of the carbonyl region of the spectra $\left(1770-1550 \mathrm{~cm}^{-1}\right)$ was conducted in order to separate overlapping bands. Following subtraction of the baseline, Gaussian peak fitting was carried out on the spectra using OriginPro 7.5 software. In each case four to five overlapping peaks were detected in this region. Their combined area and shape were close to those of the original bands.

\section{Thermal Degradation Study}

Crystalline CIP was heated to the onset $\left(\sim 265^{\circ} \mathrm{C}\right)$ and endset $\left(\sim 276^{\circ} \mathrm{C}\right)$ of melting at $10{ }^{\circ} \mathrm{C} / \mathrm{min}$ using a Mettler Toledo DSC. Cryomilled CIP was also heated to the melting endset $\left(\sim 284{ }^{\circ} \mathrm{C}\right)$. Crystalline CIP was then heated by HSDSC to $300{ }^{\circ} \mathrm{C}$ at $500{ }^{\circ} \mathrm{C} / \mathrm{min}$ using a PerkinElmer Diamond DSC. The samples were diluted with mobile phase and analyzed by HPLC. The entire study was carried out at least in triplicate for each sample. 


\section{High-Performance Liquid Chromatography (HPLC)}

The content of CIP was measured with a Shimadzu ${ }^{\circledR}$ 10Avp HPLC system (Kyoto, Japan), using the liquid chromatography method for ciprofloxacin described in the British Pharmacopoeia. ${ }^{12} \mathrm{~A}$ Luna $5 \mathrm{u}$ C8 column was used, with a length of $250 \mathrm{~mm}$, internal diameter of $4.6 \mathrm{~mm}$ and $5 \mu \mathrm{m}$ particle size. The mobile phase consisted of 13 volumes of acetonitrile and 87 volumes of a 2.45 $\mathrm{g} / \mathrm{L}$ solution of phosphoric acid, previously adjusted to $\mathrm{pH} 3.0$ with triethylamine. An injection volume of $10 \mu \mathrm{L}$ and flow rate of $1.5 \mathrm{~mL} / \mathrm{min}$ for $17 \mathrm{~min}$ was used. A Shimadzu SPD-10Avp UV-VIS Detector at $278 \mathrm{~nm}$ was used to detect the drug. A standard curve was prepared in order to find the concentration of CIP.

\section{Dynamic Vapor Sorption (DVS)}

DVS analysis was carried out on partially amorphous CIP that had been spray dried in ethanol/water, using an Advantage-1 automated gravimetric vapor sorption analyzer (Surface Measurement Systems Ltd., London, UK). The temperature was maintained at $25.0 \pm 0.1{ }^{\circ} \mathrm{C}$. Approximately $10 \mathrm{mg}$ of powder was added to the sample basket and placed in the instrument. This was equilibrated at $0 \%$ relative humidity $(\mathrm{RH})$ until a constant mass was obtained $(\mathrm{dm} / \mathrm{dt} \leq$ $0.002 \mathrm{mg} / \mathrm{min})$. The reference mass was recorded and sorption-desorption analysis was then carried out between 0 and $90 \% \mathrm{RH}$, in steps of $10 \% \mathrm{RH}$. At each stage, the sample mass was equilibrated $(\mathrm{dm} / \mathrm{dt} \leq 0.002 \mathrm{mg} / \mathrm{min}$ for at least $10 \mathrm{~min})$ before the $\mathrm{RH}$ was changed. An isotherm was calculated from the complete sorption and desorption profile. The sample was analyzed by PXRD when it reached $80 \% \mathrm{RH}$ (during the sorption stage) and also when it returned to $0 \% \mathrm{RH}$ at the end of the study.

\section{Crystallographic Analysis}


The crystallographic data was analyzed in detail using Platon (version 150216), ${ }^{29}$

CrystalExplorer (version 3.1) ${ }^{30}$ and Mercury ${ }^{\circledR}$ (version 3.5.1) ${ }^{31}$ using the 2015 version of the Cambridge Structural Database (CSD) software.

\section{Computational Methods}

Gaussian03 software ${ }^{32}$ was used to optimize the structures of CIP_UI (gas phase) and CIP_ZW (water). Due to the instability of CIP_ZW in the gas phase, solvation effects during minimization of this structure were achieved implicitly through application of the integral equation formalism polarizable continuum model (IEFPCM). The B3LYP/6-311++G(d,p) level of density functional theory (DFT) was applied in all cases. No constrains on the geometry of molecules was imposed. Initial geometries were minimized using the $6-31++\mathrm{G}(\mathrm{d}, \mathrm{p})$ basis set and re-optimized. The GaussView03 package was then applied to visualize the frontier molecular orbitals and Mulliken charges.

The following global electronic descriptors were calculated according to Koopmans' theorem, ${ }^{33}$ assuming that electron affinity (A) can be expressed in terms of HOMO (Highest Occupied Molecular Orbital) orbital energy ( $\left.\mathrm{E}_{\mathrm{HOMO}}\right)$, while ionization energy (I) can be expressed as LUMO (Lowest Unoccupied Molecular Orbital) orbital energy ( $\left.\mathrm{E}_{\mathrm{LUMO}}\right)$. Therefore global reactivity descriptors, including energy band gap $(\Delta \mathrm{E})$, absolute electron negativity $(\chi)$, chemical potential $(\mu)$, absolute hardness $(\eta)$, global softness $(S)$ and electrophilicity index $(\omega)$ can be determined using equations $1-6:^{34,35}$
$\Delta E=(I-A) \quad$ eq 1
$\chi=\frac{I+A}{2} \quad$ eq 2
$\mu=-\chi \quad$ eq 3 


$$
\begin{array}{ll}
\eta=\frac{I-A}{2} & \text { eq } 4 \\
S=\frac{1}{\eta} & \text { eq } 5 \\
\omega=\frac{\mu^{2}}{2 \eta} & \text { eq } 6
\end{array}
$$

\section{Statistical Analysis}

Statistical analysis was carried out using Minitab ${ }^{\circledR} 16$ software. Data was analyzed using oneand two-sample Student t-tests, or one-way analysis of variance (ANOVA) with Tukey's multiple comparison test (Tukey's honestly significant difference, or HSD). ${ }^{36}$ A p-value of $\leq$ 0.05 was considered significant.

\section{Results and Discussion}

\section{Crystal Forms of Ciprofloxacin}

As previously mentioned, anhydrous CIP is known to exist in two crystalline forms. It may be unionized (CCDC number 757817, CSD refcode UHITOV01) $)^{5}$ or zwitterionic (CCDC number 712460, CSD refcode COVPIN01). ${ }^{6}$ Readers are referred to the publications of Mahapatra et al ${ }^{5}$ and Fabbiani et al, ${ }^{6}$ respectively, for detailed crystallographic information on these structures. The structure overlay of CIP_UI and CIP_ZW, produced using the crystal structures from the CCDC (no. 757817 and no. 712460 respectively), is shown in Figure 2. 


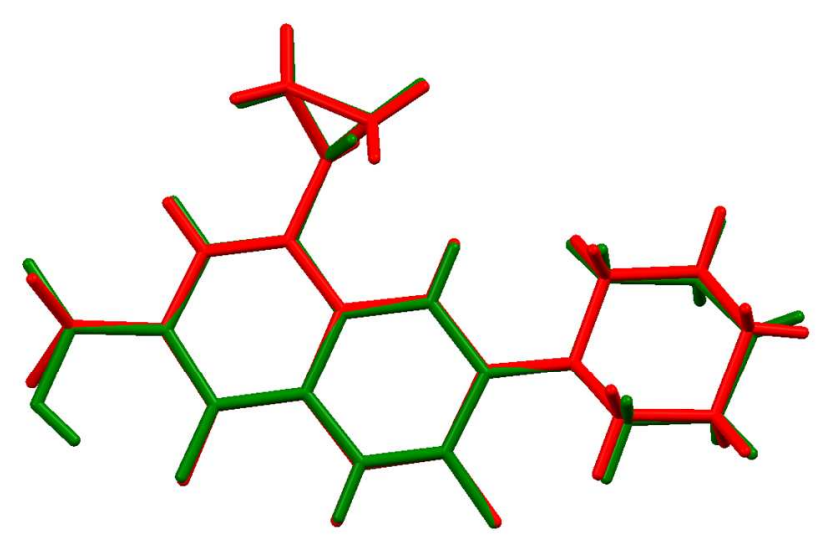

Figure 2. Structure overlay of CIP_UI (green) and CIP_ZW (red).

The root mean square deviation (RMSD) provides a measure of the difference between two sets of values (usually comparing observed data to estimated data). The RMSD is defined as the square root of the mean squared error. In Mercury ${ }^{\circledR}$ this is used to measure the geometric difference between packing features or packing patterns in crystal structures. Three pairs of atoms, C1, C7 and F1, were used to compare these structures, resulting in a RMSD of 0.0264 . The distances between the equivalent atoms were $0.023 \AA$ for $\mathrm{F} 1,0.027 \AA$ for $\mathrm{C} 1$ and $0.029 \AA$ for $\mathrm{C} 15$, indicating that there is no significant conformational change between the two forms of CIP molecule.

CIP_UI belongs to the triclinic crystal system and P-1 space group. ${ }^{5}$ An $\mathrm{O}-\mathrm{H} \bullet \bullet \bullet \mathrm{O}$ intramolecular hydrogen bond is formed between the hydrogen of the carboxylic acid and the neighboring ketone oxygen (Figure 3a). This interaction is also found in CIP salts, where it stabilizes the protonated carboxylic acid and reduces the acidity of this group. ${ }^{37}$ The unionized drug also contains an intermolecular $\mathrm{N}-\mathrm{H} \bullet \bullet \mathrm{N}$ hydrogen bond between the secondary amine groups of neighboring molecules; therefore each molecule is part of a dimer. This head-to-head interaction is absent from CIP salts. In addition, intermolecular interactions between the carbonyl oxygen of the carboxylic acid and various $\mathrm{C}-\mathrm{H}$ groups are present. ${ }^{5}$ 
(a)

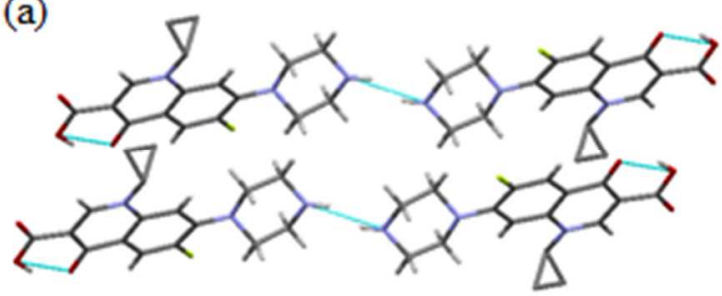

(b)

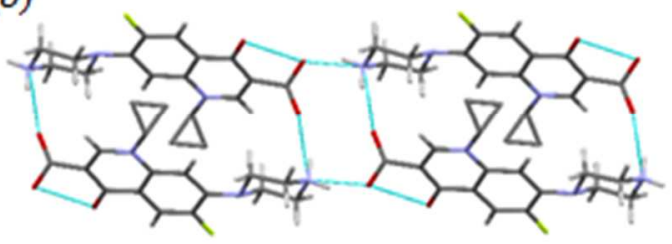

(c)
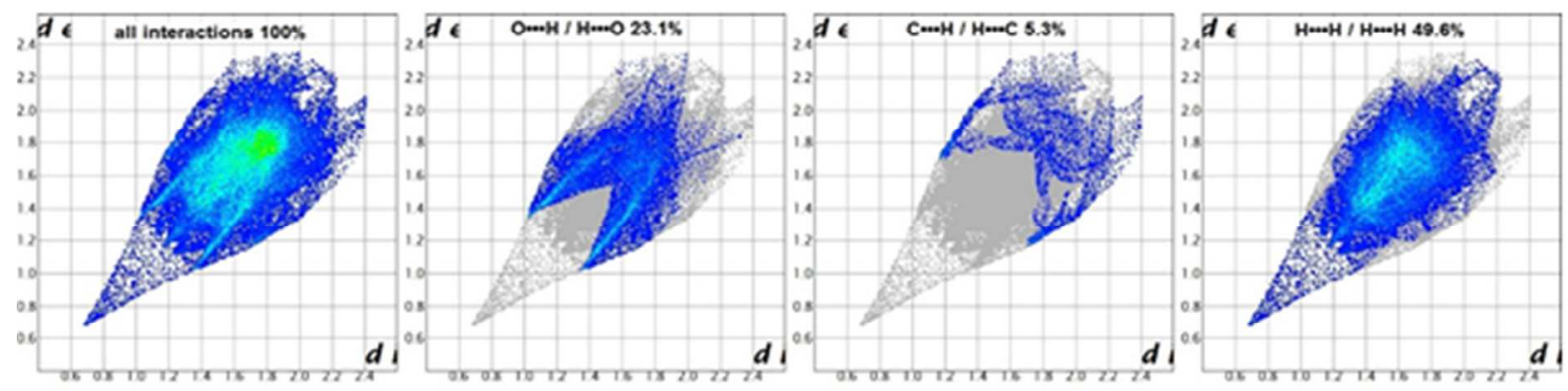

(d)
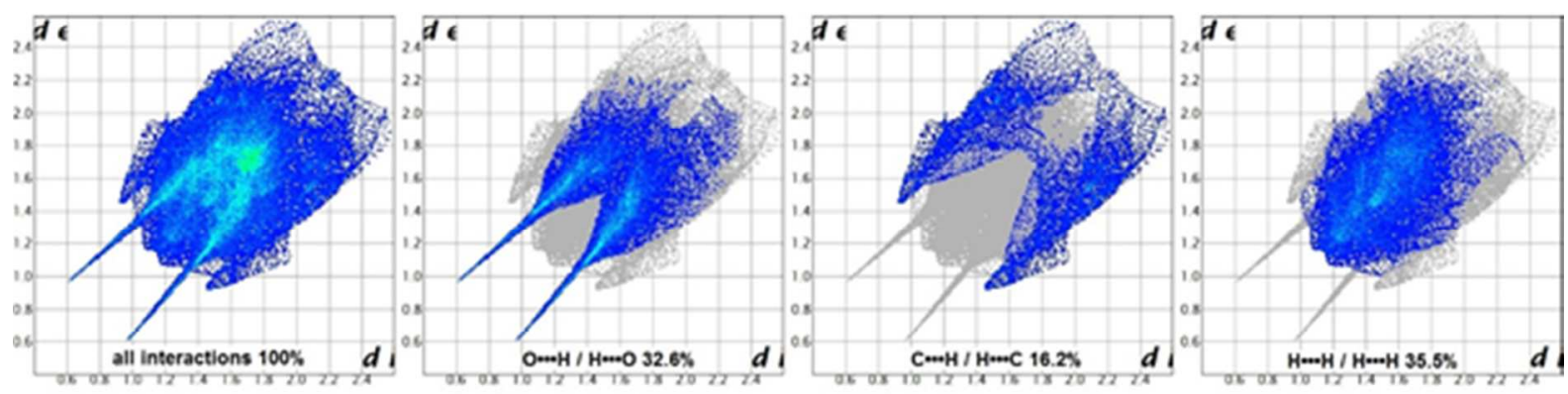

Figure 3. Principal hydrogen bond network in (a) CIP_UI and (b) CIP_ZW. Hirshfeld analysis as fingerprint plots with percent contribution of reciprocal interactions for (c) CIP_UI and (d) CIP_ZW.

In CIP_ZW on the other hand, intermolecular ionic bonds are formed between the positively charged piperazine nitrogen and negatively charged carboxylate oxygen atom of two neighboring molecules. This head-to-tail interaction results in the formation of a one-dimensional supramolecular chain of molecules parallel to the a-axis of the unit cell (Figure 3b). In addition, adjacent chains are connected by strong intermolecular $\mathrm{NH}^{+} \bullet \bullet \mathrm{O}^{-}$hydrogen bonds, forming twodimensional layers which extend along the (- $\left.\begin{array}{lll}-1 & 0 & 1\end{array}\right)$ planes of the drug and are not interlinked., ${ }^{6,38}$ 
Each CIP molecule is therefore linked to both neighboring and adjacent molecules, resulting in a tetramer-like structure. Intermolecular $\mathrm{C}-\mathrm{H} \pi-\pi$ interactions between the aromatic rings and between the aromatic ring and cyclopropyl group are also present. ${ }^{38}$ Such intermolecular bonding enables dense packing of the molecules in the crystal and the formation of a strong crystal lattice. ${ }^{39}$ A weak halogen $\mathrm{C}-\mathrm{H} \bullet \bullet \cdot \mathrm{F}$ bond is also present in the crystal structures of CIP_UI and CIP_ZW. A detailed analysis of the H-bonds present in both forms of CIP can be found in Table SI.1.

Hirshfeld analysis of the crystal packing of CIP_UI and CIP_ZW, using the fingerprint plot feature, reveals that their crystal structures are stabilized by $23.1 \%$ and $32.6 \%$ of reciprocal $\mathrm{O} \bullet \bullet \mathrm{H}$ interactions, respectively. The contribution of other principal interactions (reciprocal $\mathrm{H} \bullet \bullet \mathrm{H}$ and $\mathrm{C} \bullet \bullet \mathrm{H} / \mathrm{H} \bullet \bullet \mathrm{C}$ ) is presented in Figure $3 \mathrm{c}$. The greater contribution of the $\mathrm{O} \bullet \bullet \mathrm{H}$ interactions in CIP_ZW confers enhanced stability to the crystal lattice of this form of CIP in comparison to that of CIP_UI. ${ }^{40}$ These combined $\mathrm{O} \bullet \bullet \cdot \mathrm{H}$ and $\mathrm{H} \bullet \bullet \cdot \mathrm{O}$ interactions are visible as "wings" in the fingerprint plot in Figure 3d. The UNI force-field calculations showed that the total packing energy for the CIP_UI and CIP_ZW crystal structures was -129.8 and -169.4 $\mathrm{kJ} / \mathrm{mol}$, respectively, and therefore the zwitterionic form of CIP (crystal) is more stable. This is consistent with the theoretical density of $1.50 \mathrm{~g} / \mathrm{cm}^{3}$ for CIP_ZW, in comparison to $1.45 \mathrm{~g} / \mathrm{cm}^{3}$ for CIP_UI (calculations performed by Platon software).

\section{Production of Amorphous Ciprofloxacin}

The production of pure amorphous CIP has not been described in the literature to date. This is most likely due to the fact that it is not suitable for processing by the most common methods of 
amorphous solid generation. For example, CIP has been reported to decompose after melting, ${ }^{9}$ which would rule out the use of melting techniques. In addition, due to its very low solubility in common solvents, solvent evaporation, spray drying and freeze drying are also quite unattractive options. Nevertheless, a number of processing techniques were evaluated in terms of their suitability to amorphize CIP.

\section{Ball Milling at Room Temperature}

While milling is often used to micronize drugs, high energy milling can be used to bring about changes in the solid state of a drug, such as conversion from the crystalline to the amorphous form. ${ }^{41}$ The CIP starting material was composed of the zwitterionic form of the drug. As can be seen from Figure 4, ball milling at room temperature for 4 hours did not produce the fully amorphous form of CIP; however it did reduce the intensity of the peaks seen in PXRD over time. As with the starting material, the peaks of ball milled CIP match those of the anhydrous zwitterion (CIP_ZW). Increasing the duration of milling to 6 hours did not decrease the intensity of the peaks further (data not shown). Upon milling, the color of CIP also changed from offwhite to pale yellow, which can be considered as mechanochromism. ${ }^{42}$

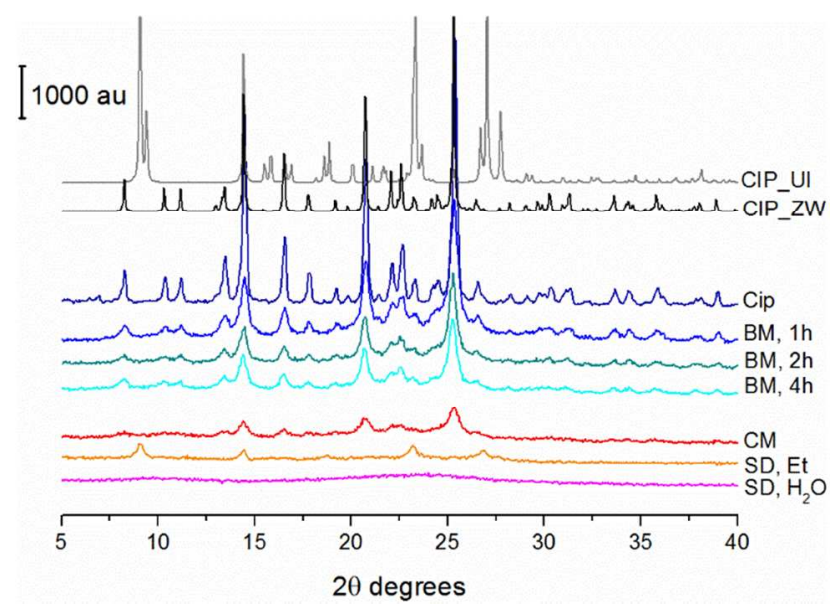


Figure 4. PXRD analysis of (from top to bottom) CIP_UI: powder pattern of unionized CIP calculated from CCDC number 757817; CIP_ZW: powder pattern of zwitterionic CIP calculated from CCDC number 712460; CIP: CIP powder "as received"; BM,1h, 2h and 4h: CIP powder "as received" ball milled for 1, 2 and 4 hours; CM: CIP powder "as received" cryomilled; SD,Et: CIP spray dried from an ethanolic solution; and $\mathrm{SD}, \mathrm{H}_{2} \mathrm{O}$ : CIP spray dried from an aqueous solution.

The most intense peak in the PXRD pattern of CIP is located at $25.32 \theta$ degrees. This peak corresponds to the (1 2 -1) crystal face, and appears in the PXRD of all of the samples which were produced by milling. The peaks at $14.4\left(\begin{array}{lll}1 & 0 & -1\end{array}\right), 20.7\left(\begin{array}{lll}1 & 0 & -2\end{array}\right)$ and $16.5\left(\begin{array}{lll}1 & 1 & 1\end{array}\right) 2 \theta$ degrees are the next most intense peaks, and also appear in the PXRD of the milled drug. During mechanical stress, such as milling, crystals will fracture along specific crystallographic slip planes. This occurs in two possible manners, depending on the shape of the crystal. It will either break along its shortest dimension or along a cleavage plane with a low attachment energy. ${ }^{43,44}$ Thus, the fracture of a crystal will occur where the interactions between adjacent planes are weakest. Slip planes are also likely to correspond to rigid crystallographic planes with a high molecular density and large d-spacing (distance between adjacent planes). ${ }^{45}\left(\begin{array}{lll}1 & 2 & -1\end{array}\right)$ seems to be the most likely cleavage plane of the CIP zwitterion, and therefore it appears as the most intense peak in the PXRD of milled CIP. This plane is illustrated in Figure 5. 


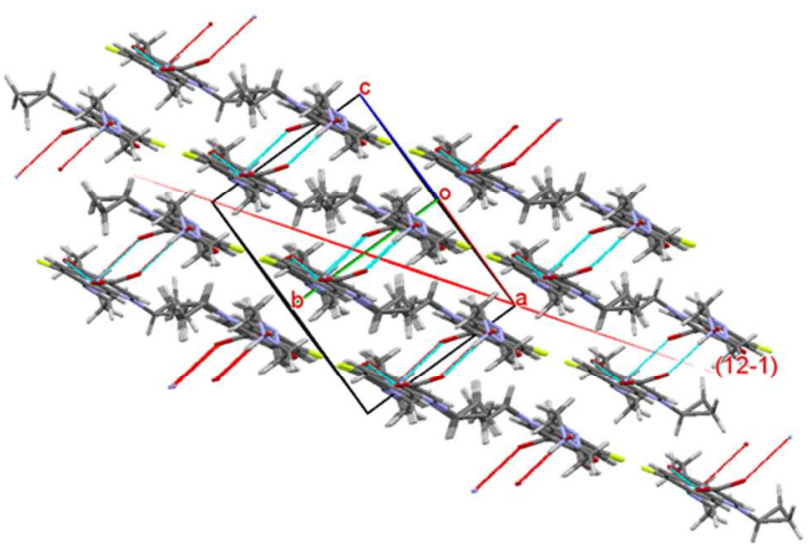

Figure 5. Cleavage plane (1 2 -1) of CIP_ZW.

\section{Cryomilling}

The inability to generate amorphous CIP when milling at room temperature may be due to the relatively high temperature at which the process was carried out. The lower the temperature used for milling, the easier it is to amorphize a drug. ${ }^{46}$ It is also well known that in order to obtain an amorphous product, milling should be performed below the $\mathrm{T}_{\mathrm{g}}$ of the drug. ${ }^{47}$ Therefore cryomilling should be a more efficient method of producing amorphous CIP than milling at room temperature. Cryomilling holds the sample at a temperature below $0{ }^{\circ} \mathrm{C}$, which helps to prevent crystallization of the sample during milling. ${ }^{48}$ As shown in Figure 4, following cryomilling CIP still had some residual crystallinity. The four most prominent peaks of the CIP zwitterion are still present in the PXRD of the cryomilled sample; however they are less intense than those obtained with the drug milled at room temperature.

\section{Spray Drying}

Spray drying was the final technique attempted in order to produce amorphous CIP. Although CIP is described as practically insoluble in water and very slightly soluble in ethanol by the British Pharmacopoeia, ${ }^{12}$ theoretically CIP can be spray dried in these solvents. However, a very 
large volume of dilute solution will be required. The sample of pure CIP produced by spray drying in ethanol/water 9:1 (v/v) possessed a small degree of residual crystallinity (Figure 4). However, in contrast to the partially amorphous CIP obtained with the other methods, this form of CIP displayed different PXRD peaks. These correspond to the simulated single crystal diffraction pattern of CIP_UI, obtained by Mahapatra et al. ${ }^{5}$ Since the starting material was zwitterionic, it was the non-aqueous nature of the solvent used for spray drying that dictated the CIP form that crystallized from, presumably, a fully amorphous intermediate. The most prominent peaks in the PXRD of CIP_UI are located at 9 (llll $\left.0 \begin{array}{lll}0 & 1\end{array}\right), 14.4\left(\begin{array}{lll}0 & 1 & 1\end{array}\right), 23.3\left(\begin{array}{lll}2 & -1 & 0\end{array}\right)$ and 27 ( 01 - 1 -3) $2 \theta$ degrees. These four peaks also appear in the PXRD of CIP spray dried in ethanol/water, at a low intensity.

Spray drying in pure water on the other hand successfully yielded CIP that was fully X-ray amorphous (Figure 4). An earlier attempt to spray dry CIP in water resulted in a partially amorphous form of the drug. As with the milled products, the PXRD peaks of this sample corresponded to those of the CIP zwitterion (data not shown). Although this method was successful at producing fully amorphous CIP, a significant disadvantage of this spray drying procedure is that $1 \mathrm{~L}$ of solution is required in order to produce just a few milligrams of sample. This is therefore a very inefficient method of generating amorphous CIP.

\section{Quench Cooling - Thermal Degradation Studies}

It was noted that upon heating CIP changes color. DSC experiments showed that at the onset of melting $\left(\sim 265^{\circ} \mathrm{C}\right)$ it is pale yellow/beige in color, whereas at the endset $\left(\sim 276{ }^{\circ} \mathrm{C}\right)$ it is dark brown. The proportion of drug that degraded in each sample under certain heating conditions is listed in Table 1. The content of CIP in the sample heated to $\sim 265^{\circ} \mathrm{C}$ (prior to melting) 
decreased slightly by $5.7 \pm 2.5 \%$, however a one-sample t-test showed that this is not statistically significantly different from the starting material CIP ( $p$-value $=0.19)$. For the CIP sample heated to $\sim 276{ }^{\circ} \mathrm{C}$ (up to the endset of melting) it was found that $26.8 \pm 8.1 \%$ of the drug had degraded. This confirms that quench cooling is not a suitable method for the production of amorphous CIP, as melting induces an unacceptable level of chemical degradation.

The use of higher heating rates should reduce degradation, as the sample will have less time to undergo structural changes. ${ }^{49}$ Indeed, when a heating rate of $500{ }^{\circ} \mathrm{C} / \mathrm{min}$ was used, a lower degree of degradation of $19.4 \%$ occurred. However, this was not statistically significantly different from the sample heated at $10^{\circ} \mathrm{C} / \mathrm{min}$, according to a two-sample t-test (p-value $=0.29$ ). A lower proportion of degradation, of $12.7 \pm 6.3 \%$, was obtained with cryomilled CIP, as this sample was only heated to the endset of the first melting peak $\left(\sim 273^{\circ} \mathrm{C}\right)$, prior to full degradation. ANOVA with Tukey's multiple comparison test showed that the level of thermal decomposition in this sample was statistically significantly different from that of crystalline CIP heated to $\sim 276{ }^{\circ} \mathrm{C}$ (post-melt) at $10{ }^{\circ} \mathrm{C} / \mathrm{min}(\mathrm{p}$-value $=0.04)$.

Table 1. Proportion of CIP that Degraded on Thermal Treatment

\begin{tabular}{|l|l|}
\hline Sample & \% Degraded \\
\hline $\begin{array}{l}\text { Crystalline CIP } \\
\text { (heated up to } \sim 265{ }^{\circ} \mathrm{C} \text { at } 10{ }^{\circ} \mathrm{C} / \mathrm{min} \text { ) }\end{array}$ & $5.7 \pm 2.5$ \\
\hline $\begin{array}{l}\text { Crystalline CIP } \\
\text { (heated up to } \sim 276{ }^{\circ} \mathrm{C} \text { at } 10{ }^{\circ} \mathrm{C} / \mathrm{min} \text { ) }\end{array}$ & $26.8 \pm 8.1$ \\
\hline $\begin{array}{l}\text { Cryomilled CIP } \\
\text { (heated up to } \sim 273{ }^{\circ} \mathrm{C} \text { at } 10{ }^{\circ} \mathrm{C} / \mathrm{min} \text { ) }\end{array}$ & $12.7 \pm 6.3$ \\
\hline Crystalline CIP Post $\mathrm{HSDSC}$ & $19.4 \pm 4.4$ \\
\hline
\end{tabular}




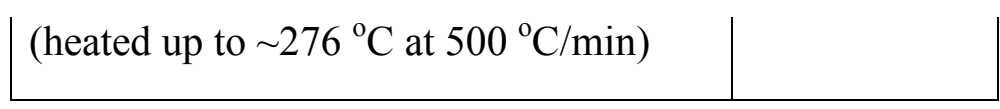

The TGA scans of crystalline and cryomilled CIP are shown in Figure SI.2. The mass of crystalline CIP decreased gradually up to a temperature of approximately $250{ }^{\circ} \mathrm{C}$. Above this temperature a steep loss in mass of $10.5 \%$ occurred due to thermal degradation. With the cryomilled sample on the other hand, an initial mass loss of $6.4 \%$ occurred between 25 and $65{ }^{\circ} \mathrm{C}$ due to water loss. The mass of this sample also decreased steeply above $250{ }^{\circ} \mathrm{C}$ due to degradation, leading to a total loss in mass of $17.3 \%$.

\section{Solid State Fourier Transform Infrared Spectroscopy}

The FTIR spectra of the CIP raw material, amorphous and partially amorphous CIP samples are shown in Figure 6a. The spectrum of raw CIP contains a peak at 1590 and $1375 \mathrm{~cm}^{-1}$, corresponding to the asymmetric and symmetric vibrations, respectively, of the carboxylate ion. ${ }^{50}$ The spectrum of CIP which was spray dried in ethanol/water, on the other hand, has a clear peak at $1722 \mathrm{~cm}^{-1}$, due to the presence of the $\mathrm{COOH}$ group. There may be some residual zwitterionic CIP present in this sample however, as small peaks matching those of the carboxylate ion of CIP may also be seen at 1590 and $1375 \mathrm{~cm}^{-1}$. The spectra of the rest of the amorphous and partially amorphous CIP samples are missing a strong peak above $1700 \mathrm{~cm}^{-1}$, due to deprotonation of the carboxylic acid. ${ }^{51}$ The asymmetric and symmetric vibrations of the $\mathrm{COO}^{-}$ group are far weaker than in the crystalline drug; however amorphous solids are known to exhibit broader bands of lower intensity than their crystalline form. ${ }^{52}$ These samples also contain a minor amount of unionized CIP, as a small peak can be seen in their spectra at around $1720 \mathrm{~cm}^{-}$ 
1. The peak at approximately $1618 \mathrm{~cm}^{-1}$ in the spectrum of CIP can be assigned to the $\mathrm{C}=\mathrm{O}$ stretch of the ketone carbonyl, ${ }^{50}$ and this peak appears in the spectra of all of the partially amorphous samples.

(a)

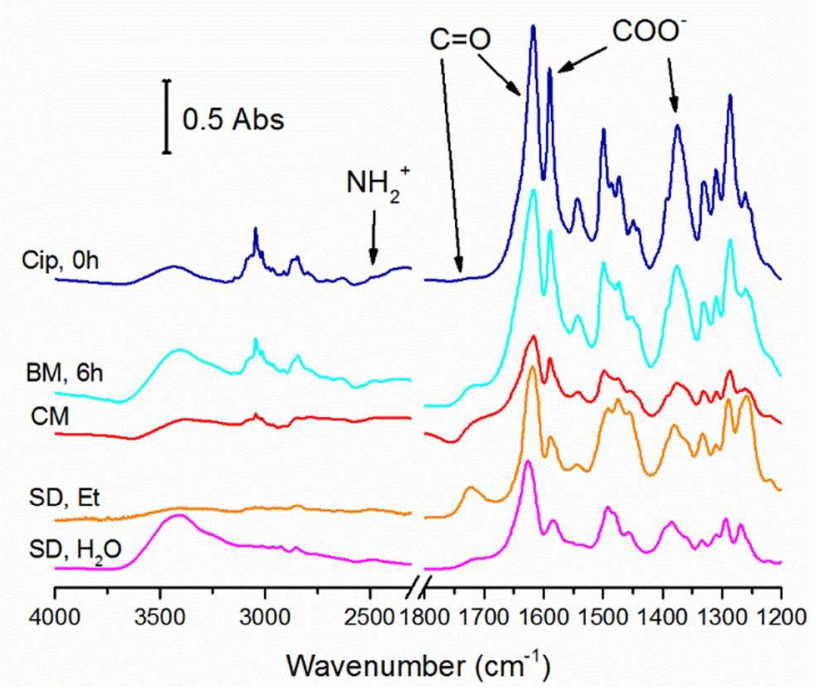

(b)

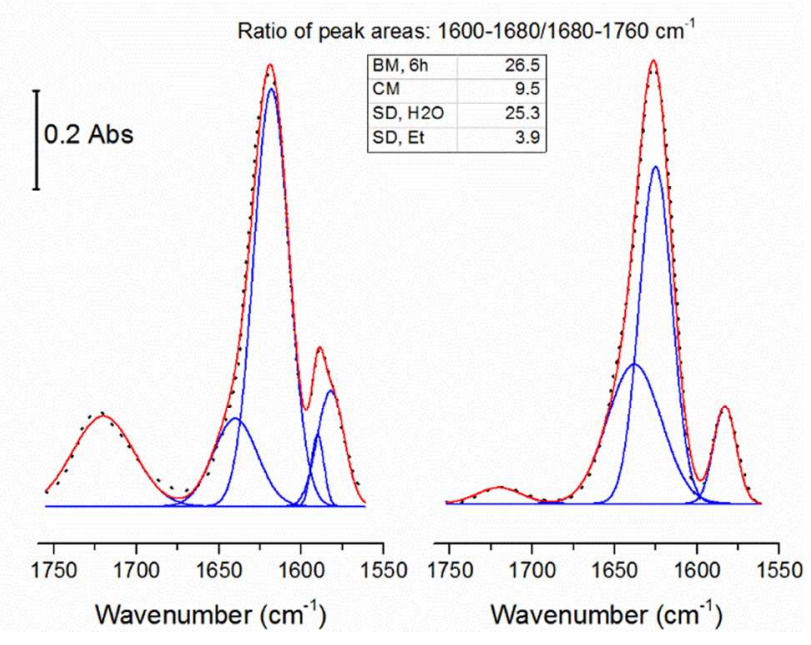

Figure 6. (a) FTIR spectra of (from top to bottom) unmilled CIP, CIP ball milled for 6 hours, CIP cryomilled, CIP spray dried from water/ethanol mixture and CIP spray dried from water. (b) Examples of peak deconvolution. CIP spray dried from ethanol/water mixture (left) and CIP 
spray dried from water (right); dotted black line: recorded spectrum, solid blue lines: deconvoluted individual Gauss peaks, and solid red line: sum of the component peaks.

The peaks in the carbonyl region of the spectra, from $1770-1550 \mathrm{~cm}^{-1}$, are quite broad, leading to overlap. In order to enhance their resolution, the spectra were deconvoluted, with Gaussian peak fitting. An example of the deconvoluted FTIR spectra obtained with spray dried CIP is shown in Figure 6 b. In each case 4-5 peaks were found in the region examined, due to different vibrations of the carbonyl groups. For all four of the disordered samples, a peak of low area is present between 1680 and $1760 \mathrm{~cm}^{-1}$, which corresponds to the unionized $\mathrm{COOH}$ group. This confirms the presence of a small amount of unionized CIP in all of these samples. The ratio of the area of the peak appearing at $1600-1680 \mathrm{~cm}^{-1}$ to that featuring between 1680 and $1760 \mathrm{~cm}^{-1}$ can be used to compare the proportion of unionized carboxylic acid present in the four samples. As suggested by the FTIR spectra shown above, the lowest ratio was obtained with CIP which was spray dried in ethanol/water, which was equal to 3.9. This was followed by cryomilled CIP, at 9.5. A much lower proportion of unionized CIP was present in the samples prepared by ball milling at room temperature and spray drying in pure water, which had a ratio of 26.5 and 25.3 , respectively. As previously mentioned, the peak at approximately $1590 \mathrm{~cm}^{-1}$ corresponds to the asymmetric vibration of the carboxylate ion. ${ }^{50}$ This peak is present at $1583-1590 \mathrm{~cm}^{-1}$ in all of the spectra, confirming the presence of the zwitterion. Two peaks were found in this area for CIP that was ball milled at room temperature and that which was spray dried in ethanol/water. This may be due to the participation of this group in hydrogen bonding.

$\mathrm{NH}_{2}{ }^{+}$stretching vibrations are present as weak bands at $2400-2600 \mathrm{~cm}^{-1}$ in the spectra shown in Figure 6a. Similar bands can be found in the FTIR spectra of CIP salts, in which the piperazine secondary amine is also ionized. ${ }^{9,53}$ This peak appears to be absent from the sample spray dried 
in ethanol/water. These spectra confirm the results of the PXRD analysis above, that is, that the CIP raw material, as well as the samples obtained by ball milling, cryomilling and spray drying in pure water, are zwitterionic. The CIP which was spray dried in ethanol/water, on the other hand, is largely unionized.

\section{Conventional Thermal Analysis}

DSC thermograms (using a heating rate of $10^{\circ} \mathrm{C} / \mathrm{min}$ ) of amorphous and partially amorphous CIP, produced by the different methods described above, are shown in Figure 7. Raw CIP displayed a sharp melting endotherm at $271.9^{\circ} \mathrm{C}$. In contrast, the drug which was ball milled at room temperature had a broad melting peak, at a lower temperature of $263.4{ }^{\circ} \mathrm{C}$, as it is more disordered than the fully crystalline starting material. There appears to be a slight exothermic event in the thermogram of this sample at about $104{ }^{\circ} \mathrm{C}$, due to crystallization of the amorphous material present.

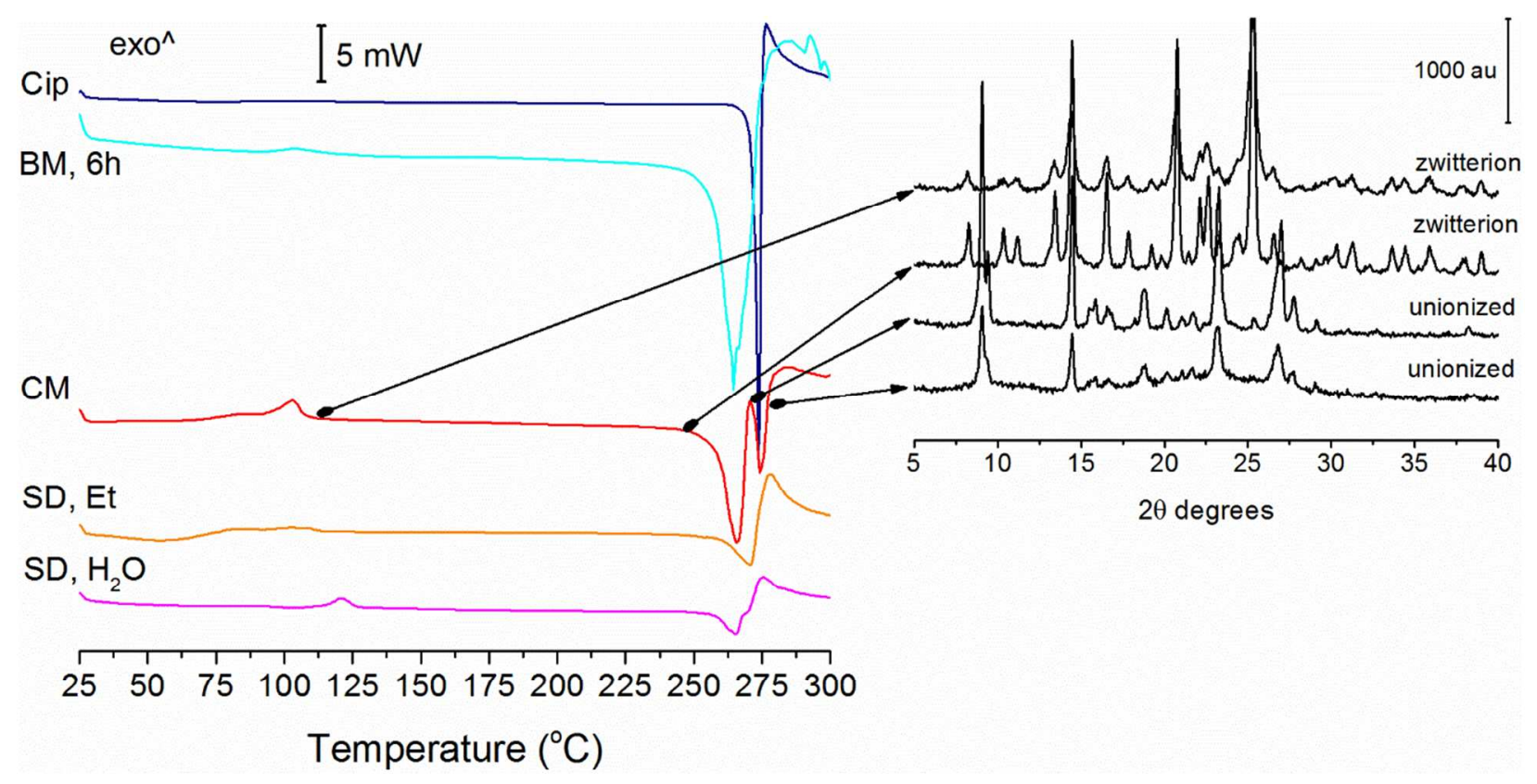


Figure 7. Conventional DSC thermograms of (from top) unmilled CIP, CIP ball milled for 6 hours, CIP cryomilled, CIP spray dried from water/ethanol mixture and CIP spray dried from water (left). The panel on the right shows the PXRD diffractograms of cryomilled CIP heated to various temperatures.

The DSC thermogram of cryomilled CIP shows a larger crystallization peak, at $103{ }^{\circ} \mathrm{C}$. Interestingly, two endothermic peaks, at 266 and $278{ }^{\circ} \mathrm{C}$, are also present. This sample was further investigated by heating it to various temperatures in the DSC instrument, and then immediately analyzing the sample by PXRD (Figure 7). As described above, the PXRD of cryomilled CIP displayed small peaks corresponding to the zwitterion. At the endset of crystallization $\left(110^{\circ} \mathrm{C}\right)$ and prior to the onset of the first melting peak $\left(251^{\circ} \mathrm{C}\right)$, the drug was found to be in the same ionized state, with an increase in crystallinity occurring as the temperature increased. However following both the first $\left(270{ }^{\circ} \mathrm{C}\right)$ and second $\left(276{ }^{\circ} \mathrm{C}\right)$ endothermic peaks, the drug was in the unionized state. FTIR analysis (data not shown) confirmed the ionization state of CIP, with the unionized carboxylic acid group producing a peak at $1726 \mathrm{~cm}^{-1}$. Therefore heating this form of CIP to a temperature near its melting point enables intermolecular proton transfer from the protonated piperazine amino group to the carboxylate anion.

These results are similar to those obtained by others with the crystalline zwitterionic form of CIP. Turel et al found that, when heated to $270{ }^{\circ} \mathrm{C}$ (before the drug melts or begins to decompose), the carboxylate absorbance bands in the FTIR spectrum of the drug disappear and are replaced by the characteristic peak of a carboxylic acid carbonyl. ${ }^{54}$ This is due to the conversion of the zwitterion to the unionized form. This was also found to be the case for CIP hexahydrate upon heating to $280{ }^{\circ} \mathrm{C} .{ }^{51}$ Similarly, Mahapatra et al claimed that heating CIP to 250 
${ }^{\circ} \mathrm{C}$ resulted in the reversible formation of unionized CIP, as shown by PXRD. ${ }^{5}$ However, in this case the changes in the PXRD pattern were incorrectly attributed to dehydration and hydration of the drug, rather than intermolecular proton transfer. We attempted to replicate these results, by heating CIP to $250,260,265$ and $270{ }^{\circ} \mathrm{C}$ by DSC and immediately carrying out PXRD analysis on the powder. However, at each stage the drug was found to still be in the ionized state. In contrast, when CIP was heated to the endset of melting (approximately $285^{\circ} \mathrm{C}$ ) and allowed to cool it was found to be X-ray amorphous (Figure SI.3a). When this sample was analyzed by DSC a $\mathrm{T}_{\mathrm{g}}$ could be seen at $94.5^{\circ} \mathrm{C}$ (Figure SI.3b). Its FTIR spectra also contained a peak at $1724 \mathrm{~cm}^{-1}$, which corresponds to the unionized $\mathrm{COOH}$ group of CIP (Figure SI.3c). This confirms that CIP converted to the unionized form.

The samples of CIP which were spray dried in ethanol/water and pure water also had broader and lower melting peaks than the crystalline drug, at 270.6 and $266.2^{\circ} \mathrm{C}$ respectively (Figure 7 ). A small crystallization peak can be seen in the thermogram of the sample spray dried in pure water at $121{ }^{\circ} \mathrm{C}$. Although the $\mathrm{T}_{\mathrm{g}}$ 's of these samples are difficult to distinguish, they appear to be located between 80 and $100{ }^{\circ} \mathrm{C}$. Crystallization occurs soon after the glass transition, suggesting that the samples are thermally unstable. Temperature-modulated DSC (StepScan ${ }^{\mathrm{TM}}$ ) was used to find the $\mathrm{T}_{\mathrm{g}}$ of the fully amorphous CIP which was spray dried in water. This technique is more sensitive to changes in specific heat capacity, such as glass transition events, than standard DSC. It can therefore be used to accurately detect weak, broad or irregularly shaped glass transitions. ${ }^{55}$ This allowed the detection of the $\mathrm{T}_{\mathrm{g}}$ at $86.7^{\circ} \mathrm{C}$ (the DSC thermogram is shown in Figure SI.4).

\section{Investigation of Proton Transfer in CIP}


HSDSC was used to analyze the partially amorphous cryomilled CIP. The use of a higher heating rate increases the sensitivity of the instrument and produces a larger step change in the thermogram during the glass transition. At a heating rate of $50-200{ }^{\circ} \mathrm{C} / \mathrm{min}$ the $\mathrm{T}_{\mathrm{g}}$ could not be seen clearly. However when this was increased to $300{ }^{\circ} \mathrm{C} / \mathrm{min}$ a glass transition was visible at $88.0{ }^{\circ} \mathrm{C}$ (Figure 8a). This was soon followed by crystallization, which shows that the sample has poor thermal stability. Increasing the heating rate did not have a significant effect on the crystallization temperature of the sample, with the onset remaining between 97.5 and $99.7^{\circ} \mathrm{C}$ for all runs. This is unusual, as crystallization is generally a function of temperature and time. Therefore the peak observed in the thermogram would be expected to shift to higher temperatures if the heating rate is increased. ${ }^{56}$ The crystallization temperature may have remained constant due to the sample having a low energy barrier for crystallization. Regardless of the heating rate used, cryomilled CIP also displayed two endothermal peaks.

(a)

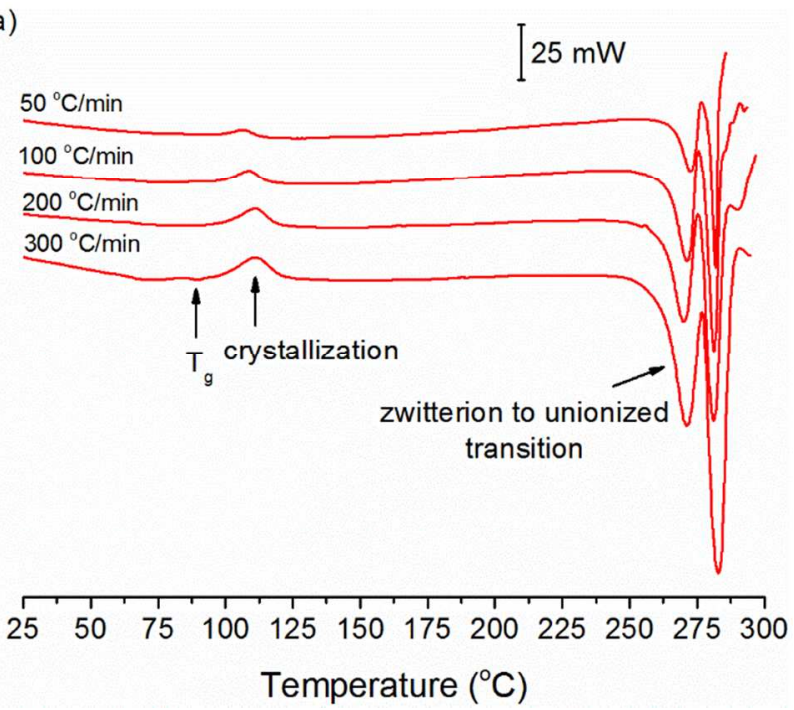


(b)

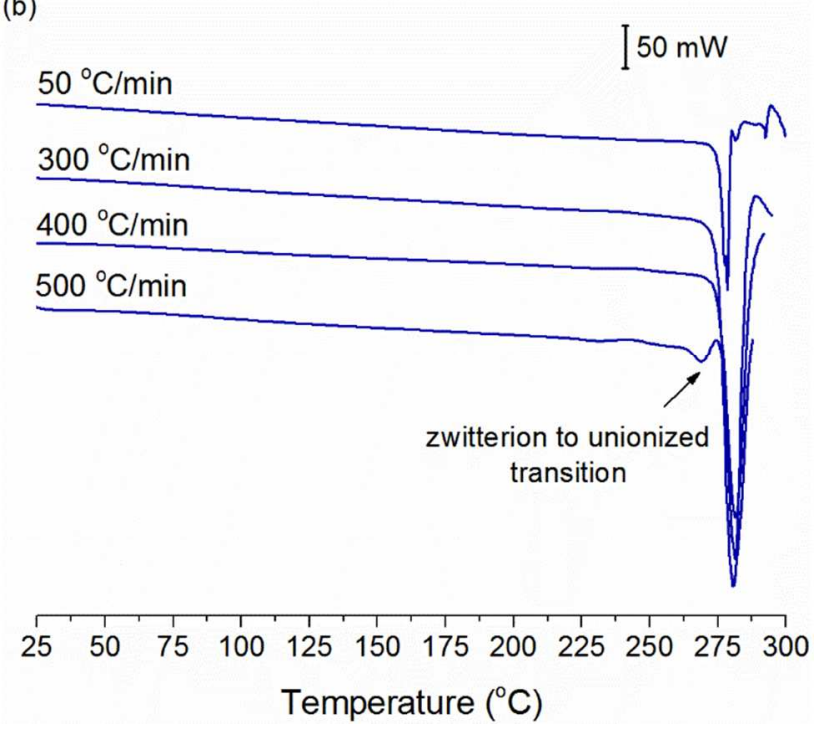

Figure 8. HSDSC of (a) cryomilled CIP and (b) crystalline CIP (as received).

Crystalline CIP was then analyzed by HSDSC, with heating rates of $50-500{ }^{\circ} \mathrm{C} / \mathrm{min}$. In DSC the change in heat flow signal seen during a transition is proportional to the heating rate. Therefore high heating rates can be used to detect low energy transitions. At heating rates of up to 400 ${ }^{\circ} \mathrm{C} / \mathrm{min}$, a single melting peak was obtained (Figure $8 \mathrm{~b}$ ). However, heating at $500{ }^{\circ} \mathrm{C} / \mathrm{min}$ enabled the elucidation of two endothermic peaks, with onsets at 269.3 and $275.6{ }^{\circ} \mathrm{C}$. These can be attributed to the transition of the zwitterion to the unionized form and melting of this form. In contrast to conventional DSC, following HSDSC at $500{ }^{\circ} \mathrm{C} / \mathrm{min}$ CIP was still crystalline, however its PXRD pattern matched that of CIP_UI. A similar endothermic peak was seen in the DSC thermogram of crystalline norfloxacin heated at $10{ }^{\circ} \mathrm{C} / \mathrm{min}$, immediately prior to melting. ${ }^{24}$

The first endothermal transition of CIP can be attributed to the transition of the zwitterion to the unionized form, and it is clearly a function of physical disorder in the sample. While both samples showed this transition, the crystalline CIP required a much higher heating rate for the transition to be noticed. Computational analysis was therefore performed to investigate the 
relative chemical stability of CIP_UI and CIP_ZW. HOMO and LUMO are key parameters related to the reactivity and chemical stability of molecules. The energy gap between HOMO and LUMO helps to describe the chemical behavior and electrical properties of molecules, with lower energies indicating higher reactivity and lower stability. ${ }^{34}$ Electron density on the HOMO/LUMO frontier orbitals of CIP_UI in the basic state is distributed through various parts of the molecule. The HOMO resides on the piperazine residue and in part on the quinoline ring, while the LUMO sits mainly on the quinoline system, stretching as far as the carboxylic acid group (Figure 9). In CIP_ZW on the other hand the HOMO/LUMO are arranged only around the quinoline ring (Figure 9). The HOMO/LUMO energy gap for CIP_UI and CIP_ZW, based on the computed structures, is 2.939 and $3.020 \mathrm{eV}$, respectively (Table 2). Therefore the difference in reactivity between the two CIP forms is small, but the slightly better stability of CIP_ZW is visible in the distribution of $\mathrm{HOMO} / \mathrm{LUMO}$ centered around the quinoline ring and not on the groups with the highest electron donor/acceptor capacity, in contrast to CIP_UI. Global reactivity parameters, such as absolute electron negativity $(\chi)$, chemical potential $(\mu)$, absolute hardness $(\eta)$, global softness (S) and electrophilicity index $(\omega)$, listed in Table 2, also indicate the better stability of CIP_ZW. Hardness is a measure of resistance to change in the electron distribution in a molecule ${ }^{57}$ thus higher values of hardness (and lower of softness) suggest greater stability of the system. The chemical potential and electrophilicity index parameters give an indication of the electrophile/nucleophile propensity to give/accept an electron. Lower values of $\mu$ and $\omega$ are typical of a nucleophile (in this case CIP_ZW), while CIP_UI will exhibit electrophilic properties, confirming that proton transfer will occur from the (positively) charged piperazine nitrogen onto the carboxylate. The crystal lattice of CIP_ZW (Figure 3) indicates that such a transfer should be facilitated by the intermolecular ionic interactions present between these 
moieties. As previously discussed, the crystal structures of unionized and zwitterionic CIP differ quite substantially. CIP_UI consists of dimers connected by head-to-head $\mathrm{N}-\mathrm{H} \cdot \bullet \cdot \mathrm{N}$ hydrogen bonds, while the molecules in CIP_ZW form head-to-tail $\mathrm{N}-\mathrm{H}_{2}{ }^{+} \cdots{ }^{-}$OOC hydrogen bonds with both neighboring and adjacent molecules. Therefore transformation between the two forms of the drug will involve reorientation of the molecules as well as proton transfer.
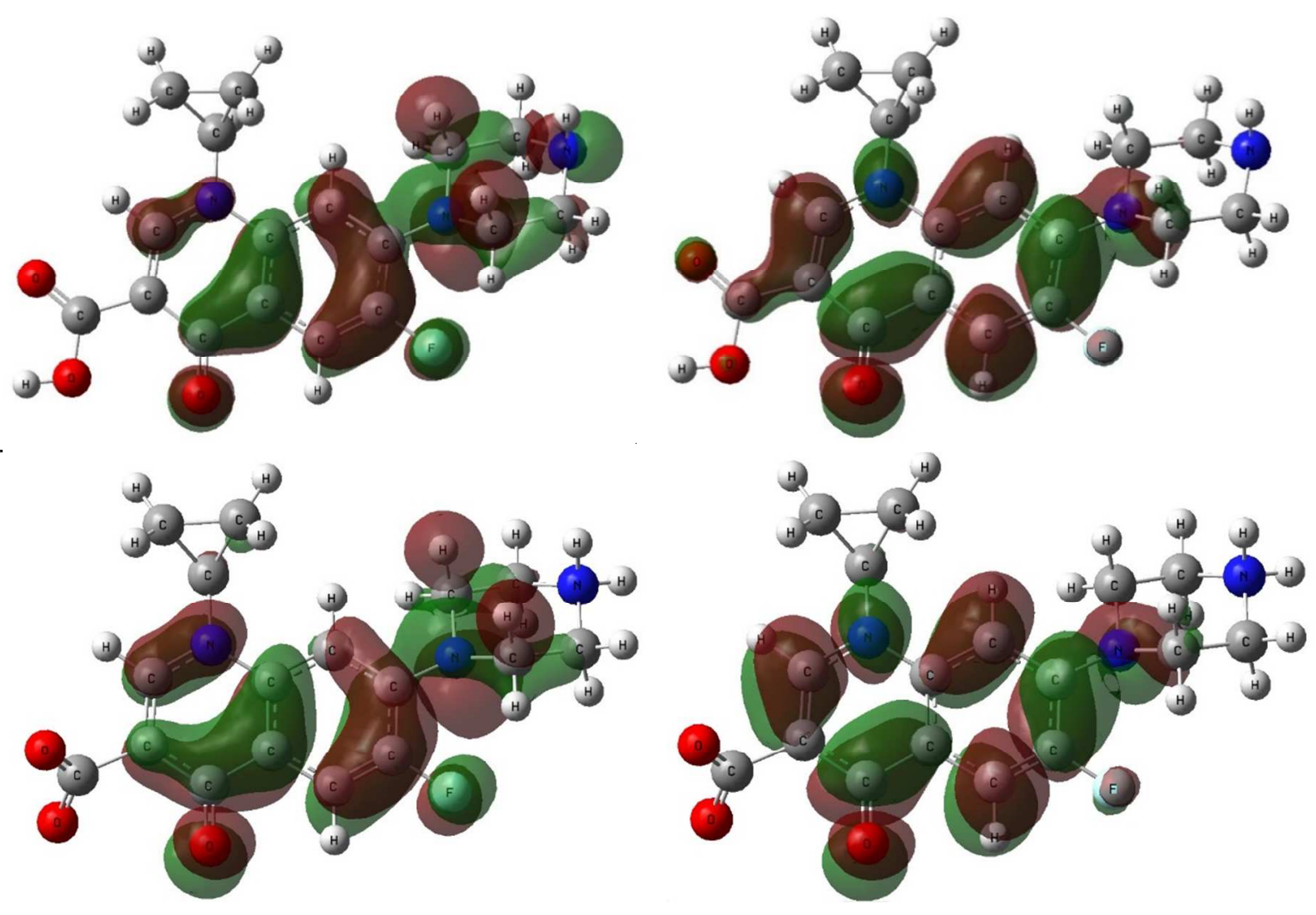

Figure 9. HOMO (left) AND LUMO (right) of CIP_UI (top) and CIP_ZW (bottom).

Table 2 Global Reactivity Parameters

\begin{tabular}{|l|l|l|l|l|l|l|l|l|}
\hline & $\begin{array}{l}\mathrm{E}_{\text {HOMO }} \\
(\mathrm{eV})\end{array}$ & $\begin{array}{l}\mathrm{E}_{\text {LUMO }} \\
(\mathrm{eV})\end{array}$ & $\begin{array}{l}\Delta \mathrm{E}^{a} \\
(\mathrm{eV})\end{array}$ & $\chi^{b}$ & $\mu^{c}$ & $\eta^{d}$ & $\mathrm{~S}^{e}$ & $\omega^{f}$ \\
\hline CIP_UI & -8.762 & -5.823 & 2.939 & 7.293 & -7.293 & 1.469 & 0.340 & 18.097 \\
\hline CIP_ZW & -8.871 & -5.850 & 3.020 & 7.361 & -7.361 & 1.510 & 0.331 & 17.938 \\
\hline
\end{tabular}


${ }^{a} \Delta \mathrm{E}$ : energy band gap; ${ }^{b} \chi$ : absolute electron negativity; ${ }^{c} \mu$ : chemical potential; ${ }^{d} \eta$ : absolute hardness; ${ }^{e} \mathrm{~S}$ : global softness; and ${ }^{f} \omega$ : electrophilicity index of CIP_UI and CIP_ZW.

Color change has been noted to occur when proton transfer is induced by external stimuli. ${ }^{42}$ This may explain why CIP changes color upon milling and when heated close to its melting point. Piroxicam is another zwitterionic drug which can undergo proton transfer upon processing. In contrast to CIP, crystalline piroxicam is unionized. It converts to the amorphous zwitterion upon cryomilling, leading to a significant change in the conformation of the piroxicam molecule. ${ }^{42}$ The unionized form of piroxicam is colorless, while the zwitterion and melt are yellow. ${ }^{58}$ The conversion of piroxicam between the unionized and zwitterionic form has been described as tautomeric polymorphism. ${ }^{58}$ The zwitterionic and unionized form of CIP may therefore be considered as tautomers, which undergo thermal and mechanically induced tautomerism. The $\Delta \mathrm{E}$ values for both forms of CIP are close to $3 \mathrm{eV}$ (Table 2). This corresponds to the absorption of 410-430 nm light, rendering the substance yellow in color, consistent with our visual observations.

\section{Physical Stability in Humid Conditions}

The partially amorphous unionized CIP, produced by spray drying in ethanol/water, was analyzed by dynamic vapor sorption (DVS) in order to investigate the effect of water absorption on the crystal structure of the drug. As can be seen from the sorption-desorption isotherm (Figure 10), partially amorphous CIP was very hygroscopic, absorbing almost $16 \%$ of its mass in water at $90 \% \mathrm{RH}$. 


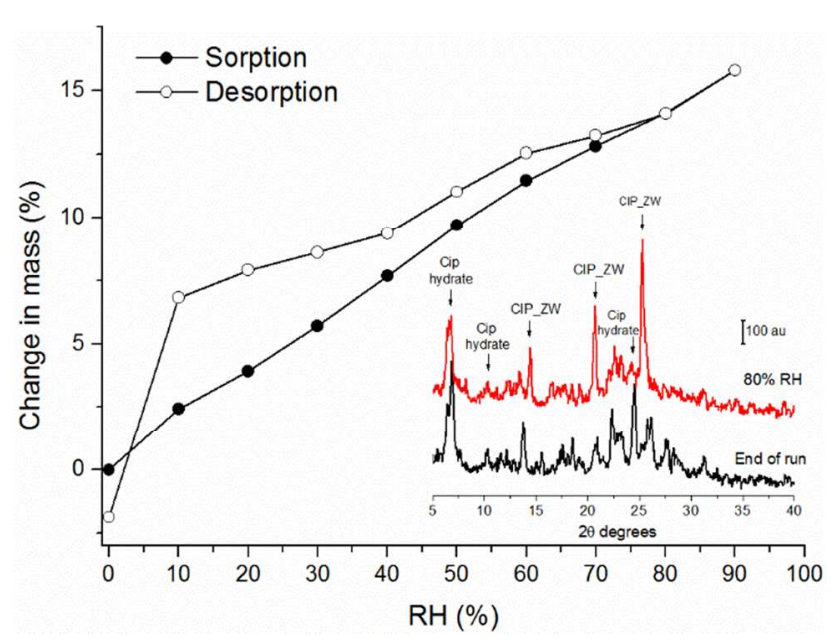

Figure 10. DVS analysis of partially amorphous CIP spray dried in ethanol/water 9:1; inset: PXRD of the sample following DVS analysis, at $80 \% \mathrm{RH}$ (on sorption, red line) and following the full sorption/desorption cycle (at $0 \% \mathrm{RH}$, black line).

The drug partially crystallized during the DVS study. This was confirmed by PXRD, which was carried out at $80 \% \mathrm{RH}$ and at the end of the run (Figure 10, inset). At $80 \% \mathrm{RH}$, the PXRD has four main peaks. The peak at 6-7 $2 \theta$ degrees corresponds to that of the CIP hydrate described by Li et al. This hydrate contains 3.5 water molecules for every molecule of CIP. ${ }^{59}$ The peaks at $14.4,20.7$ and $25.32 \theta$ degrees on the other hand match the most prominent peaks of CIP_ZW. At the end of the analysis, at $0 \% \mathrm{RH}$, the PXRD of the drug also contained the pronounced peak of the 3.5 hydrate at 6-7 $2 \theta$ degrees. Peaks at 13.8 and $24.52 \theta$ degrees also belong to the hydrate, and those at 20.8 and $22.42 \theta$ to the zwitterion. Hydrates often crystallize more readily than the anhydrous form of a drug, as the molecules can pack together more easily. This may be due to their symmetry, changes in conformation, and the formation of hydrogen bonds between the drug and water molecules. ${ }^{60}$ When hydrated, CIP also exists in the zwitterionic form. ${ }^{51}$ Therefore, while anhydrous CIP can exist in the unionized form, when exposed to water it reverts to the zwitterion. Similar results were obtained with norfloxacin, with the unionized drug 
converting to the zwitterion when exposed to high humidity. This proton transfer was reversible upon heating above $155^{\circ} \mathrm{C} .{ }^{61}$ Incorporation of water molecules has been found to lower the energy barrier for proton transfer, which enables this conversion to occur upon hydration. ${ }^{62}$

\section{Conclusions}

The production of pure amorphous CIP is very challenging due to its poor solubility, strong crystal lattice and thermal degradation. Despite these barriers, amorphous CIP was successfully prepared by spray drying in water, while partially amorphous products were obtained by ball milling, cryomilling and spray drying in an ethanol/water mixture. The unionized form of the drug was obtained using the latter method, whereas all others resulted in the zwitterion. Proton transfer, resulting in transformation to the unionized drug, was visualized using HSDSC. This was shown to occur upon heating the zwitterion to its melting point, and occurred more readily in disordered systems. Although the calculated differences between unionized and zwitterionic CIP, such as molecular conformation, packing energy and the HOMO/LUMO energy gap, were found to be small, the higher degree of hydrogen bonding in the crystal lattice of the charged drug results in greater stability and lower reactivity. Thus the zwitterion is the preferred form of CIP in the crystalline state.

\section{Associated Content}

\section{Supporting Information}


ORTEP crystal structures of CIP_UI and CIP_ZW; hydrogen bonding geometry, intermolecular interactions, packing arrangements, intermolecular potentials, packing energy, and Unified (UNI) pair-potential parameters of CIP_UI and CIP_ZW; TGA of crystalline and cryomilled CIP; PXRD, DSC and FTIR of cooled CIP post-melt; and StepScan ${ }^{\mathrm{TM}}$ DSC thermogram of CIP spray dried in water. This material is available free of charge via the Internet at http://pubs.acs.org.

\title{
Author Information
}

\section{Corresponding Author}

*Phone: +35318962787, email: 1tajber@tcd.ie.

\author{
Author Contributions \\ Crystallographic investigations were carried out by NM. All other experiments were carried out \\ by HM and LT. The manuscript was written through contributions of all authors. All authors \\ have given approval to the final version of the manuscript.
}

\section{Funding Sources}

Funding for this research was provided by Science Foundation Ireland under grant No. 12/RC/2275 (Synthesis and Solid State Pharmaceuticals Centre).

Notes 
The authors declare no competing financial interest.

\title{
Acknowledgements
}

The authors would like to thank Prof. Graeme Watson, TCD, for access to Gaussian03 software.

\begin{abstract}
Abbreviations
CIP, ciprofloxacin; CIP_UI, unionized anhydrous ciprofloxacin; CIP_ZW, zwitterionic anhydrous ciprofloxacin.
\end{abstract}

\section{References}

(1) Appelbaum, P. C.; Hunter, P. A. Int. J. Antimicrob. Agents 2000, 16, 5-15.

(2) Sanders, C. C.; Sanders, W. E.; Goering, R. V. Am. J. Med. 1987, 82, 2-11.

(3) Grüneberg, R. N.; Felmingham, D.; O’Hare, M. D.; Robbins, M. J.; Perry, K.; Wall, R. A.; Ridgway, G. L. J. Antimicrob. Chemother. 1988, 22 Suppl C, 9-19.

(4) Gay, J. D.; DeYoung, D. R.; Roberts, G. D. Antimicrob. Agents Chemother. 1984, 26, 9496.

(5) Mahapatra, S.; Venugopala, K. N.; Guru Row, T. N. Cryst. Growth Des. 2010, 10, 18661870. 
(6) Fabbiani, F. P. A.; Dittrich, B.; Florence, A. J.; Gelbrich, T.; Hursthouse, M. B.; Kuhs, W. F.; Shankland, N.; Sowa, H. CrystEngComm 2009, 11, 1396-1406.

(7) Webb, M. S.; Boman, N. L.; Wiseman, D. J.; Saxon, D.; Sutton, K.; Wong, K. F.; Logan, P.; Hope, M. J. Antimicrob. Agents Chemother. 1998, 42, 45-52.

(8) Breda, S. A.; Jimenez-Kairuz, A. F.; Manzo, R. H.; Olivera, M. E. Int. J. Pharm. 2009, 371, 106-113.

(9) Paluch, K. J.; McCabe, T.; Müller-Bunz, H.; Corrigan, O. I.; Healy, A. M.; Tajber, L. Mol. Pharm. 2013, 10, 3640-3654.

(10) Caco, A.; Varanda, F.; Pratas de Melo, M.; Dias, A.; Dohrn, R.; Marrucho, I. Ind. Eng. Chem. Res. 2008, 47, 8083-8089.

(11) Zhang, C.-L.; Zhao, F.; Wang, Y. J. Mol. Liq. 2010, 156, 191-193.

(12) British Pharmacopoeia Commission. In Volume I \& II; The Stationery Office: London, 2016.

(13) Tehler, U.; Fagerberg, J. H.; Svensson, R.; Larhed, M.; Artursson, P.; Bergström, C. A. S. J. Med. Chem. 2013, 56, 2690-2694.

(14) Yu, L. Adv. Drug Deliv. Rev. 2001, 48, 27-42.

(15) Hancock, B. C.; Parks, M. Pharm. Res. 2000, 17, 397-404.

(16) Al-Obaidi, H.; Buckton, G. AAPS PharmSciTech 2009, 10, 1172-1177.

(17) Andronis, V.; Yoshioka, M.; Zografi, G. J. Pharm. Sci. 1997, 86, 346-351. 
(18) Hancock, B. C.; Zografi, G. Pharm. Res. 1993, 10, 1262-1267.

(19) Makower, B.; Dye, W. B. J. Agric. Food Chem. 1956, 4, 72-77.

(20) Aso, Y.; Yoshioka, S.; Zhang, J.; Zografi, G. Chem. Pharm. Bull. (Tokyo). 2002, 50, 822826.

(21) Cheow, W. S.; Hadinoto, K. J. Colloid Interface Sci. 2012, 367, 518-526.

(22) Cheow, W. S.; Hadinoto, K. Langmuir 2012, 28, 6265-6275.

(23) Osman, R.; Kan, P. L.; Awad, G.; Mortada, N.; El-Shamy, A.-E.; Alpar, O. Int. J. Pharm. 2013, 449, 44-58.

(24) Šuštar, B.; Bukovec, N.; Bukovec, P. J. Therm. Anal. 1993, 40, 475-481.

(25) Barbas, R.; Prohens, R.; Puigjaner, C. J. Therm. Anal. Calorim. 2007, 89, 687-692.

(26) Duan, J.; Vogt, F. G.; Li, X.; Hayes, D.; Mansour, H. M. Int. J. Nanomedicine 2013, 8, $3489-3505$.

(27) Jie, Y.; Xin, H. Stable levofloxacin hydrochloride compound. CN102351881 A, 2012.

(28) Hong, C. Y.; Kim, Y. K.; Chang, J. H.; Kim, S. H.; Choi, H.; Nam, D. H.; Kim, Y. Z.; Kwak, J. H. J. Med. Chem. 1997, 40, 3584-3593.

(29) Spek, A. J. Appl. Crystallogr. 2003, 36, 7-13.

(30) Wolff, S.; Grimwood, D.; McKinnon, J.; Turner, M.; Jayatilaka, D.; Spackman, M. CrystalExplorer (Version 3.1), University of Western Australia, 2012.

(31) Macrae, C. F.; Edgington, P. R.; McCabe, P.; Pidcock, E.; Shields, G. P.; Taylor, R.; 
Towler, M.; van de Streek, J. J. Appl. Crystallogr. 2006, 39, 453-457.

(32) Frisch, M.; Trucks, G.; Schlegel, H.; Scuseria, G.; Robb, M.; Cheeseman, J.; Montgomery, J.; Vreven, T, J.; Kudin, K.; Burant, J.; et al. Gaussian 03, Revision C.02; Gaussian, Inc., Wallingford CT, 2004.

(33) Koopmans, T. Physica 1934, 1, 104-113.

(34) Pandey, J.; Prajapati, P.; Shimpi, M. R.; Tandon, P.; Velaga, S. P.; Srivastava, A.; Sinha, K.; Khan, E.; Shukla, A.; Srivastava, A.; et al. RSC Adv. 2016, 6, 74135-74154.

(35) Klopman, G. J. Am. Chem. Soc. 1968, 90, 223-234.

(36) Mullins, E. Statistics for the quality control chemistry laboratory; The Royal Society of Chemistry: Cambridge, 2003.

(37) Sun, J.; Sakai, S.; Tauchi, Y.; Deguchi, Y.; Chen, J.; Zhang, R.; Morimoto, K. Eur. J. Pharm. Biopharm. 2002, 54, 51-58.

(38) Mafra, L.; Santos, S. M.; Siegel, R.; Alves, I.; Paz, F. A. A.; Dudenko, D.; Spiess, H. W. J. Am. Chem. Soc. 2012, 134, 71-4.

(39) Wassvik, C. M.; Holmén, A. G.; Draheim, R.; Artursson, P.; Bergström, C. A. S. J. Med. Chem. 2008, 51, 3035-3039.

(40) Martin, A. D.; Britton, J.; Easun, T. L.; Blake, A. J.; Lewis, W.; Schröder, M. Cryst. Growth Des. 2015, 15, 1697-1706.

(41) Yang, Z.; Nollenberger, K.; Albers, J.; Qi, S. Mol. Pharm. 2014, 11, 2453-2465. 
(42) Sheth, A. R.; Lubach, J. W.; Munson, E. J.; Muller, F. X.; Grant, D. J. W. J. Am. Chem. Soc. 2005, 127, 6641-6651.

(43) Ho, R.; Naderi, M.; Heng, J. Y. Y.; Williams, D. R.; Thielmann, F.; Bouza, P.; Keith, A. R.; Thiele, G.; Burnett, D. J. Pharm. Res. 2012, 29, 2806-2816.

(44) Modi, S. R.; Dantuluri, A. K. R.; Perumalla, S. R.; Sun, C. C.; Bansal, A. K. Cryst. Growth Des. 2014, 14, 5283-5292.

(45) Sun, C. C.; Kiang, Y.-H. J. Pharm. Sci. 2008, 97, 3456-3461.

(46) Descamps, M.; Willart, J. F.; Dudognon, E.; Caron, V. J. Pharm. Sci. 2007, 96, 13981407.

(47) De Gusseme, A.; Neves, C.; Willart, J. F.; Rameau, A.; Descamps, M. J. Pharm. Sci. 2008, 97, 5000-5012.

(48) Macfhionnghaile, P.; Hu, Y.; Gniado, K.; Curran, S.; Mcardle, P.; Erxleben, A. J. Pharm. Sci. 2014, 103, 1766-1778.

(49) Gaisford, S.; Buanz, A. B. M. J. Therm. Anal. Calorim. 2011, 106, 221-226.

(50) Dorofeev, V. L. Pharm. Chem. J. 2004, 38, 698-702.

(51) Turel, I.; Bukovec, P.; Quirós, M. Int. J. Pharm. 1997, 152, 59-65.

(52) Heinz, A.; Strachan, C. J.; Gordon, K. C.; Rades, T. J. Pharm. Pharmacol. 2009, 61, 971988.

(53) Parojčić, J.; Stojković, A.; Tajber, L.; Grbić, S.; Paluch, K. J.; Djurić, Z.; Corrigan, O. I. J. 
Pharm. Sci. 2011, 100, 5174-5184.

(54) Turel, I.; Bukovec, P. Thermochim. Acta 1996, 287, 311-318.

(55) Cassel, B.; Packer, R. http://www.perkinelmer.com/CMSResources/Images/4474834TCH_DSCandDSC8500.pdf(accessed Sep 1, 2015).

(56) Thomas, L. C. Am. Lab. 2001, 33.

(57) Vektariene, A.; Vektaris, G.; Svoboda, J. Arch. Org. Chem. 2009, 311-329.

(58) Wales, C.; Thomas, L. H.; Wilson, C. C. CrystEngComm 2012, 14, 7264-7274.

(59) Li, X.; Zhi, F.; Hu, Y. Int. J. Pharm. 2007, 328, 177-182.

(60) Vippagunta, S. R.; Brittain, H. G.; Grant, D. J. W. Adv. Drug Deliv. Rev. 2001, 48, 3-26.

(61) Hu, T.-C.; Wang, S.-L.; Chen, T.-F.; Lin, S.-Y. J. Pharm. Sci. 2002, 91, 1351-1357.

(62) Kakkar, R.; Katoch, V. Int. J. Quantum Chem. 1999, 74, 327-336. 


\section{For Table of Contents Use Only}

The Two Faces of Ciprofloxacin: Investigation of Proton Transfer in Solid State Transformations

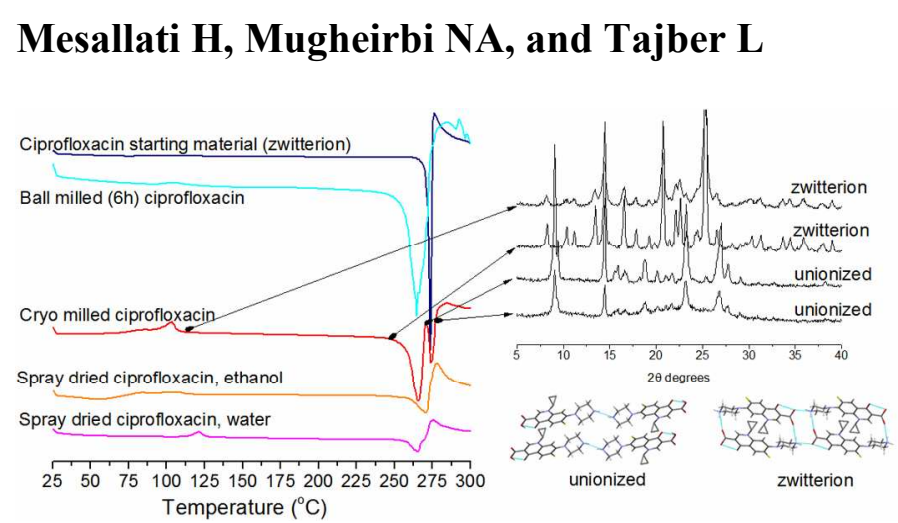

\section{Synopsis}

This work describes the solid state transformations of ciprofloxacin, with particular emphasis on the ionization state (zwitterionic or unionized) of this molecule. Ciprofloxacin proved to be very difficult to amorphize, and only spray drying in pure water resulted in a fully amorphous product. This study provides insight into the proton transfer which can occur in the solid state. 